\title{
Seismo-Tsunamigenic Ionospheric Hole Triggered by M 9.0 2011 off the Pacific Coast of Tohoku Earthquake
}

\author{
Masashi Kamogawa ${ }^{1, *}$, Yoshihiro Kakinami ${ }^{2,3}$, Shigeto Watanabe ${ }^{4}$, Jann-Yenq Liu ${ }^{3}$, \\ and Yasuyuki Watanabe ${ }^{1}$ \\ ${ }^{1}$ Department of Physics, Tokyo Gakugei University, Tokyo, Japan \\ ${ }^{2}$ Institute of Seismology and Volcanology, Hokkaido University, Japan \\ ${ }_{3}^{3}$ Institute of Space Science, National Central University, Jhongli, Taiwan \\ ${ }^{4}$ Department of Cosmoscience, Hokkaido University, Sapporo, Japan
}

Received 25 May 2011, accepted 14 November 2011

\begin{abstract}
Giant earthquake and tsunami widely disturbed ionospheric plasma via acoustic gravity waves. During the M 9.0 2011 off the Pacific coast of Tohoku earthquake, the ionospheric disturbances were generated by co-seismic epicentral ground/sea surface motion, Rayleigh-wave traveling, and tsunami-wave traveling. In addition, seismo-tsunamigenic ionospheric hole, widely sudden depression of ionospheric total electron content, was observed. The ionospheric hole gradually disappeared within roughly a few tens minutes.
\end{abstract}

Key words: Earthquake, Ionospheric disturbance, Acoustic gravity wave, Rayleigh wave, Tsunami, Ionospheric hole

Citation: Kamogawa, M., Y. Kakinami, S. Watanabe, J. Y. Liu, and Y. Watanabe, 2012: Seismo-tsunamigenic ionospheric hole triggered by M 9.02011 off the Pacific coast of Tohoku earthquake. Terr. Atmos. Ocean. Sci., 23, 327-331, doi: 10.3319/TAO.2011.11.14.01(AA)

\section{INTRODUCTION}

The ionosphere is always affected by solar and magnetospheric activities. The ionosphere is often disturbed by large earthquakes and tsunamis as well (Davies 1990). When ground and sea surface motion caused by the earthquake and tsunami excites acoustic gravity waves in the atmosphere (see Watada 2009), the acoustic gravity waves propagate into the ionosphere and disturb ionospheric plasma. The disturbances originated from the ground/sea surface motion are observed initially with ionosondes and high-frequency (HF) Doppler sounding systems (e.g., Bolt 1964) and recently with measurement using the total electron content (TEC) with Ground Positioning System (GPS) (e.g., Ducic et al. 2003). As an extraordinary case, the M 9.1 2004 Sumatra-Andaman earthquake (Sumatra EQ) caused large-scale ionospheric disturbances. Co-seismic epicentral ionospheric disturbances associated with rupture processes (Heki et al. 2006), ionospheric disturbances generated by travelling Rayleigh waves (Liu et al. 2006a) and tsunami waves (Liu et al. 2006b) were reported. Furthermore, acous-

\footnotetext{
* Corresponding author

E-mail:kamogawa@u-gakugei.ac.jp
}

tic gravity wave oscillation between lithosphere and ionosphere was observed for four hours, one hour after the mainshock (Choosakul et al. 2009).

The M 9.0 Tohoku earthquake (Tohoku EQ) was a megathrust-type which occurred on March 11 of 2011 at 0546 (universal time: UT) in the western Pacific Ocean. The epicenter was located $72 \mathrm{~km}$ away from the Oshika Peninsula and the focal depth was $32 \mathrm{~km}$. The Tohoku EQ resembles the Sumatra EQ in their magnitudes and as a megathurst subduction type. Therefore, the similar large-scale seismogenic and tsunamigenic ionospheric disturbances are expected. In this letter, we briefly report not only the seismo-tsunamigenic ionospheric disturbance but also the seismo-tusnamigenic ionospheric hole in the M 9.0 Tohoku EQ which are observed with GPS-TEC.

\section{OBSERVATION}

The GPS is used to measure integrated electron density along a ray path between a satellite and receiver using dual frequency (1575.42 and $1222.60 \mathrm{MHz}$ ) radio signals. The integrated electron density, termed slant TEC, is converted to a vertical TEC (henceforth TEC), considering the elevation 
angle of GPS satellite and assuming that the ionosphere exists as a thin layer at $350 \mathrm{~km}$, termed ionospheric surface (Liu et al. 1996). Since there are several factors such as the satellite and receiver instrumental biases, we used the Global Ionospheric Map (GIM) developed by the Jet Propulsion Laboratory (Mannucci et al. 1998) as a reference to define the biases. Values of instrumental biases are estimated by comparing minimum values of GIM TEC at the receiver location with those of observed TEC approximately from 400 to 600 (local time: LT) (Kakinami et al. 2009). The point that the ray path from a GPS satellite to a ground-based receiver intercepts the ionospheric surface is named as a ionospheric point. Each ionospheric point which acts as a monitoring station measuring the TEC is employed to detect the ionospheric disturbances. Footprint of the ionospheric point on Earth's surface is termed subionospheric point (SIP).

GPS data are provided by the Geographical Survey Institute (GSI) of Japan which has installed a nationwide GPS array with more than 1000 receivers, GPS Earth Observation Network (GEONET) (ftp://terras.gsi.go.jp/). Sampling time of the GPS data record is 30 seconds.

\section{RESULT AND DISCUSSION}

At the time of mainshock of the Tohoku EQ, several visible satellites were in transit over Japan. For example, six visible satellites (satellite numbers 05, 09, 15, 21, 26 and 27) relayed their elevation angles from one of the receiving stations near the epicenter, 0044 , are $29.1^{\circ}, 54.6^{\circ}, 67.0^{\circ}, 41.6^{\circ}$, $40.1^{\circ}$, and $78.5^{\circ}$ (Fig. 1a). Figure $1 \mathrm{~b}$ shows a time-series of slant TEC of satellite number 26 for four receiving stations after the mainshock with reference TEC curves of the 2-day previous orbit which spatially and temporally corresponds to the orbit of satellite 26. Although Dst indices of both the orbits are about -20 and - $80 \mathrm{nT}$ (see World Data Centers for Geomagnetism, Kyoto University, http://wdc.kugi.kyoto-u. ac.jp/dst realtime/201103/index-j.html), both the slant TEC of satellite 26 show roughly the similar variation but about $30 \mathrm{TECu}\left(1 \mathrm{TECu}=1 \times 10^{16}\right.$ electron $\left.\mathrm{m}^{-2}\right)$ offset existed at the mainshock time. The difference might be caused by magnetic storm. In the present study, both the EQ-day and reference curves are set up to zero at the time of the mainshock. From two curves from each station, the following features arise. The initial enhancement of TEC with about $1 \mathrm{TECu}$ amplitude appeared about 9 minutes after the mainshock. After this enhancement, a sudden large depression of TEC developed within about 2 minutes. The amplitude of this depression reached about $5 \mathrm{TECu}$. The depression with a four-minute periodic signature disappeared within roughly 40 minutes at 0044 station. The intensity of the depression was large near the epicenter. Spatial distribution of the slant TEC difference between EQ day and reference day shown in Fig. 2 also indicates that the depression was localized near the epicenter.

Figure 3 shows epicentral distance of (a) seismometer and (b) SIP versus UT with the observed intensity and highpass filtered (22.5 min.) TEC difference between EQ day and reference day. The broadband seismograph recorded in the F-net network (National Research Institute for Earth Science and Disaster Prevention; http://www.fnet.bosai.go.jp/) is used. Because from Fig. 3 the velocities of Rayleigh wave and ionospheric disturbance propagation are around 3.4 and $3.0 \mathrm{~km} \mathrm{~s}^{-1}$, the initial enhancement of TEC is Rayleigh wave origin. After the ionospheric disturbances were triggered by
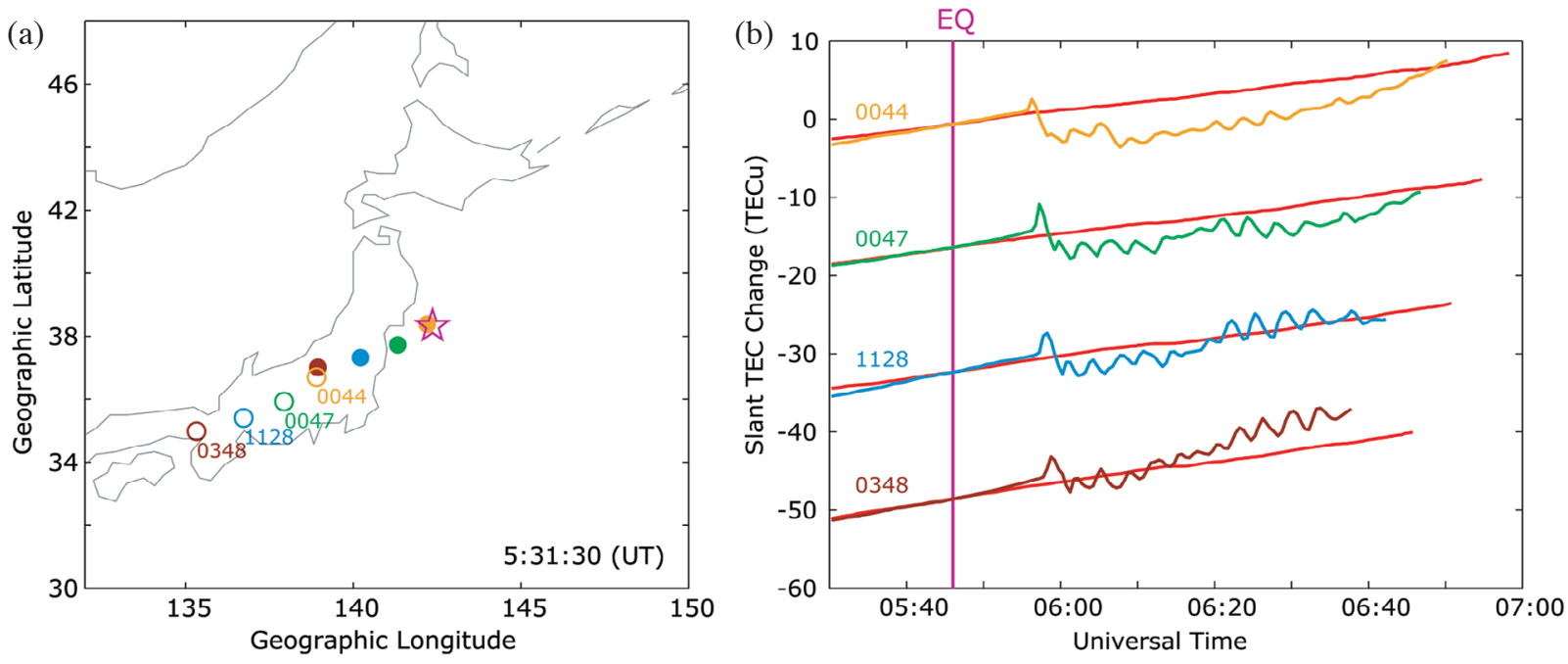

Fig. 1. (a) Location of receivers and subionospheric points for satellite 26 at the time of the mainshock. Open and solid circles denote GPS receiving stations and the corresponding SIP. The star indicates the epicenter of the Tohoku EQ. The numbers 0044, 0047, 1128, and 0348, assigned as receiving station codes, denote the GPS receiving stations located at Minakami, Gunma prefecture, Minowa, Nagano prefecture, Gifu, Gifu prefecture, and Inagawa, Hyogo prefecture, respectively. (b) Time-series of slant TEC and observed at the four GPS receiving stations after the mainshock of the Tohoku EQ with reference curves (red). Each time-series is drawn with shifting $18 \mathrm{TECu}$. 

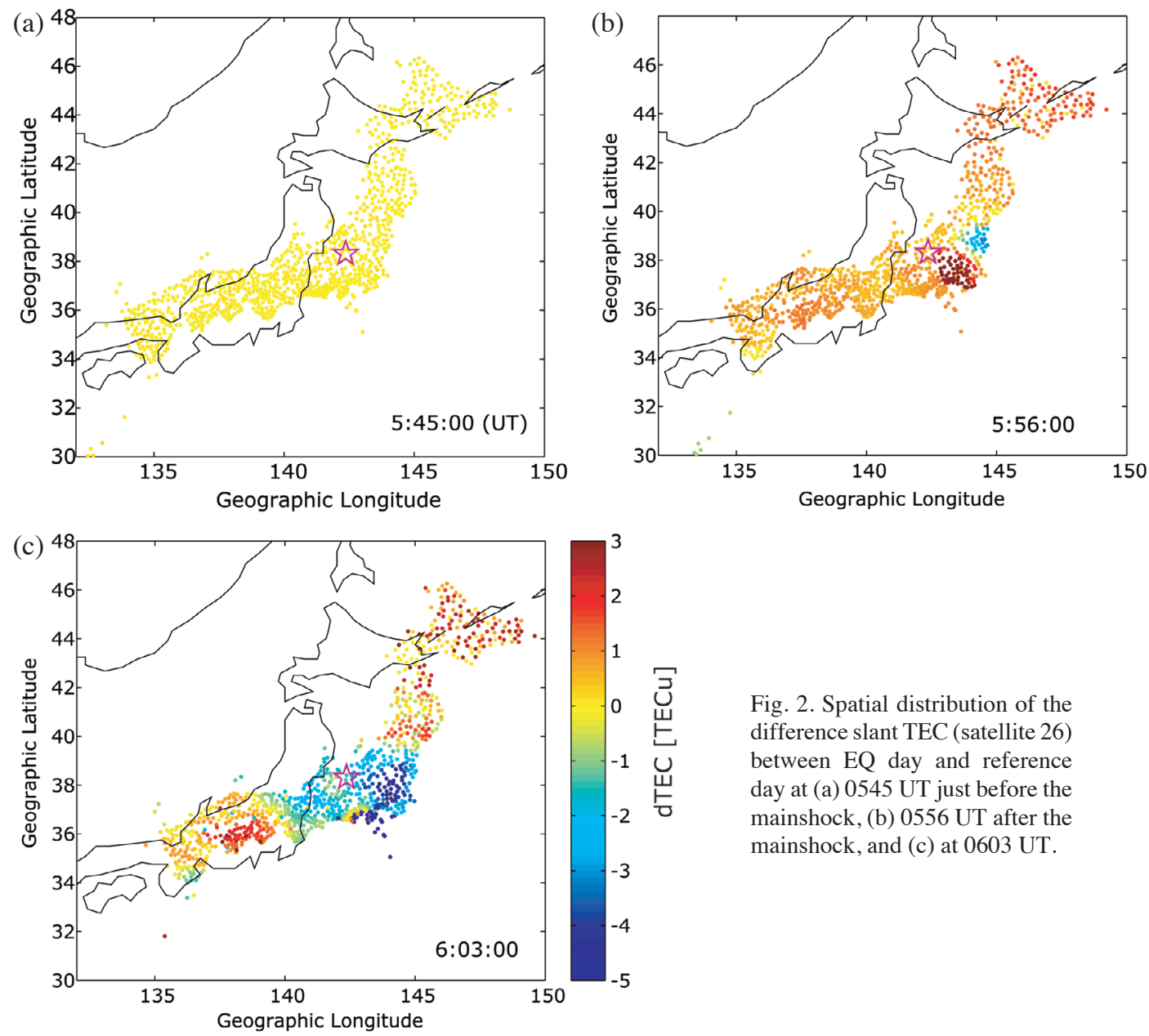

Fig. 2. Spatial distribution of the difference slant TEC (satellite 26) between EQ day and reference day at (a) 0545 UT just before the mainshock, (b) $0556 \mathrm{UT}$ after the mainshock, and (c) at 0603 UT.
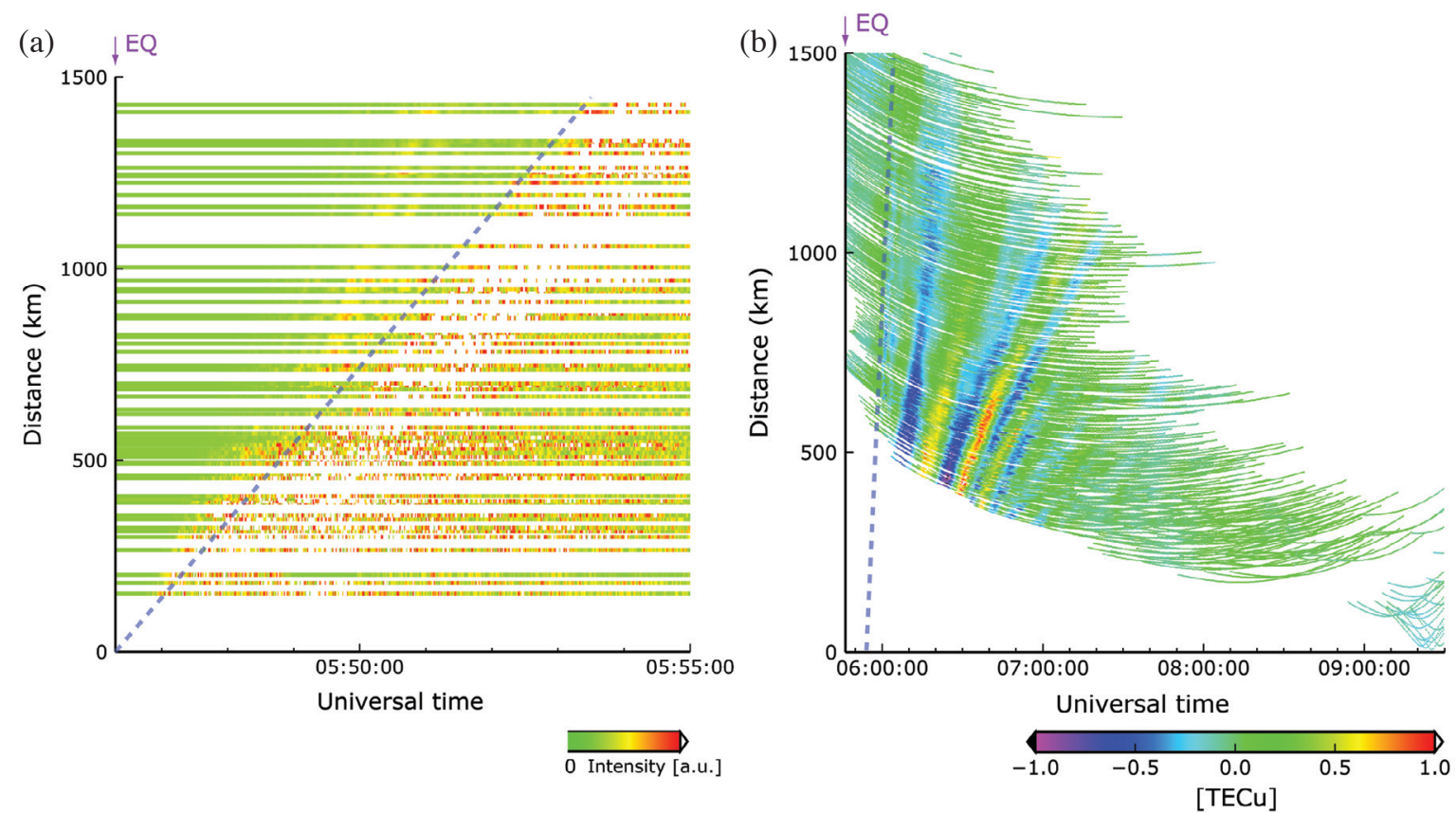

Fig. 3. (a) Epicentral distance of seismometer versus UT with the observed intensity indicated by color gradation. For a clear display, the intensity is an absolute value of the recorded output raw data. The dotted line shows Rayleigh waves. (b) Epicentral distance of SIP versus UT with the highpass filtered TEC indicated by color gradation. The dotted line shows ionospheric disturbance generated by Rayleigh waves. 
a Rayleigh wave, a few acoustic gravity wave modes appeared with velocities such as $0.75,0.30$, and $0.15 \mathrm{~km} \mathrm{~s}^{-1}$. The different origin time estimated from Fig. $3 \mathrm{~b}$ implies that tsunami-generated acoustic gravity waves were excited.

Based upon a spectrum analysis of a residual slant TEC time-series from least-squares parabolic fitting curve after the mainshock, two predominant periods were found as shown in Fig. 4. One is around $4.5 \mathrm{mHz}$, which follows the previous works (e.g., Heki et al. 2006). The other is around $0.7 \mathrm{mHz}$.

The results of this analysis admittedly depend on reference curves. For example, when the different zero points for EQ day and reference day are taken at a different time, a pre-seismic-like signature also appears. In order to avoid a discussion of pre-seismic ionospheric disturbance (see Kamogawa 2006), the zero point for them is taken at the time of mainshock.

\section{CONCLUSION}

Seismo-tsunamigenic ionospheric hole, widely sudden depression of TEC, was observed after the acoustic gravity waves triggered by the Tohoku EQ reached ionospheric surface. The ionospheric hole gradually disappeared within a few tens minutes. Besides the ionospheric disturbances caused by the co-seismic epicentral ground/sea surface motion, Rayleigh-wave traveling, and tsunami-wave traveling, and the giant earthquake produced the ionospheric hole.

Acknowledgements We thank Ms. Kaori Mochizuki (Tokyo Gakugei University) for her assistance in this work. GEONET GPS data and F-net data were provided by the Geographical Survey Institute of Japan and National Research Institute for Earth Science and Disaster Prevention of Japan. This research was partially supported by the Ministry of Education, Science, Sports and Culture, Grant-in-Aid for Young Scientists (B), No. 21710180, 2009 (Masashi Kamogawa), and Scientific Research (C), No. 20510171, 2008 (Masashi Kamogawa), Observation and Research Program for Prediction of Earthquakes and Volcanic Eruptions, 2009 (Masashi Kamogawa and Yoshihiro Kakinami), Heiwa Nakajima Foundation, 2011 (Masashi Kamogawa, Yoshihiro Kakinami, and Jann-Yenq Liu), and the National Science Council project NSC 98-2116-M-008-006-MY3 grant of the National Central University (Yoshihiro Kakinami and Jann-Yenq Liu).

\section{REFERENCES}

Bolt, B. A., 1964: Seismic air waves from the great 1964 Alaskan earthquake. Nature, 202, 1095-1096, doi: 10. 1038/2021095a0. [Link]

Choosakul, N., A. Saito, T. Iyemori, and M. Hashizume, 2009: Excitation of 4-min periodic ionospheric varia-

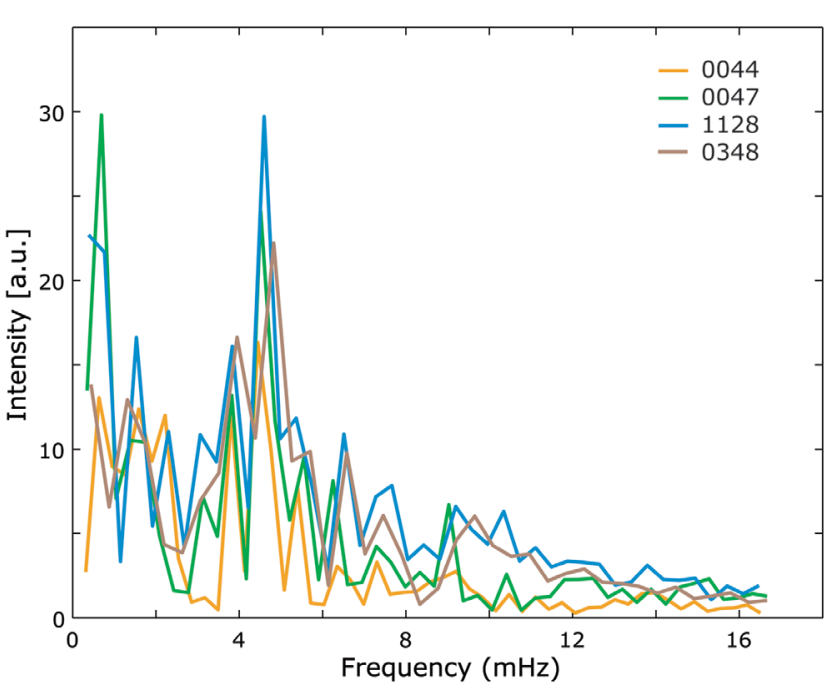

Fig. 4. Spectrum analysis of time-series of residual slant TEC at 0044, 0047,1128 , and 0348 station. Colors of this figure denote the stations corresponding to those of Fig. 1.

tions following the great Sumatra-Andaman earthquake in 2004. J. Geophys. Res., 114, A10313, doi: 10.1029/ 2008JA013915. [Link]

Davies, K., 1990: Ionospheric Radio, Peter Peregrinus Ltd, London.

Ducic, V., J. Artru, and P. Lognonné, 2003: Ionospheric remote sensing of the Denali earthquake Rayleigh surface waves. Geophys. Res. Lett., 30, 1951-1954, doi: 10.1029/2003GL017812. [Link]

Heki, K., Y. Otsuka, N. Choosakul, N. Hemmakorn, T. Komolmis, and T. Maruyama, 2006: Detection of ruptures of Andaman fault segments in the 2004 great Sumatra earthquake with coseismic ionospheric disturbances. $J$. Geophys. Res., 111, B09313, doi: 10.1029/2005JB00 4202. [Link]

Kakinami, Y.,C.H.Chen,J.Y.Liu,K.I.Oyama,W.H.Yang, and S. Abe, 2009: Empirical models of Total Electron Content based on functional fitting over Taiwan during geomagnetic quiet condition. Ann. Geophys., 27, 33213333, doi: 10.5194/angeo-27-3321-2009. [Link]

Kamogawa, M., 2006: Preseismic lithosphere-atmosphereionosphere coupling. Eos, Trans., AGU, 87, 417, doi: 10.1029/2006EO400002. [Link]

Liu, J. Y., H. F. Tsai, and T. K. Jung, 1996: Total electron content obtained by using the Global Positioning System. Terr. Atmos. Ocean. Sci., 7, 107-117.

Liu, J. Y., Y. B. Tsai, S. W. Chen, C. P. Lee, Y. C. Chen, H. Y. Yen, W. Y. Chang, and C. Liu, 2006a: Giant ionospheric disturbances excited by the M9.3 Sumatra earthquake of 26 December 2004. Geophys. Res. Lett., 33, L02103, doi: 10.1029/2005GL023963. [Link]

Liu, J. Y., Y. B. Tsai, K. F. Ma, Y. I. Chen, H. F. Tsai, C. H. Lin, M. Kamogawa, and C. P. Lee, 2006b: Iono- 
spheric GPS total electron content (TEC) disturbances triggered by the 26 December 2004 Indian Ocean tsunami. J. Geophys. Res., 111, A05303, doi: 10.1029/20 05JA011200. [Link]

Mannucci, A. J., B. D. Wilson, D. N. Yuan, C. H. Ho, U. J. Lindqwister, and T.F. Runge, 1998: A global mapping technique for GPS-derived ionospheric total electron content measurements. Radio Sci., 33, 565-582, doi: 10.1029/97RS02707. [Link]

Watada, S., 2009: Radiation of acoustic and gravity waves and propagation of boundary waves in the stratified fluid from a time-varying bottom boundary. J. Fluid Mech., 627, 361-377, doi: 10.1017/S00221120090059 53. [Link] 